\title{
The Impact of Methylphenidate on QbTest Performance of Children with ADHD: A Retrospective Clinical Study
}

This article was published in the following Dove Press journal: Neuropsychiatric Disease and Treatment

\author{
Rajna Knez $\mathbb{D}^{\prime}$ \\ Dejan Stevanovic $\mathbb{D D}^{2}$ \\ Salmir Nasic $\mathbb{D}^{3}$ \\ Ana Doric (iD ${ }^{4}$ \\ Elisabet Wentz $\mathbb{D}^{5}$
}

'Department of Pediatrics, Skaraborgs Hospital, Skövde, Sweden; Sahlgrenska Academy, Institute of Neuroscience and Physiology, University of Gothenburg, Gothenburg, Sweden; ${ }^{2}$ Psychiatry Department, Clinic for Neurology and Psychiatry for Children and Youth, Belgrade, Serbia; ${ }^{3}$ Research \& Development Centre, Skaraborgs Hospital, Skövde, Sweden; ${ }^{4}$ Department of Psychology, Faculty of Humanity and Social Sciences, University of Rijeka, Rijeka, Croatia; ${ }^{5}$ Sahlgrenska Academy, Institute of Neuroscience and Physiology, University of Gothenburg, Gothenburg, Sweden
Correspondence: Dejan Stevanovic Psychiatry Department, Clinic for Neurology and Psychiatry for Children and Youth, Dr Subotic 6a, Belgrade II 000 , Serbia

Tel +38I 69 24I 2006

Fax +38I II 2658355

Email stevanovic.dejan79@gmail.com
Introduction: The Quantified behavior Test (QbTest), which combines a continuous performance task (CPT) and motion tracking, provides data for the core signs of attentiondeficit/hyperactivity disorder (ADHD): attention, hyperactivity, and impulsivity. This study aimed to evaluate the performance of children and adolescents with ADHD on the QbTest before and after a single methylphenidate (MPH) dose.

Subjects and Methods: This retrospective chart review study included data from 149 children and 215 adolescents who completed the QbTest. A summary index of the CPT and motion capture data on the QbTest is provided by three cardinal parameters: QbActivity, QbImpulsivity, and QbInattention. The test was performed twice on the same day, before and up to three hours after MPH intake. A decrease by $\geq 0.5$ in a cardinal parameter score was considered an improvement, whereas an increase by $\geq 0.5$ a deterioration.

Results: QbActivity improvement after MPH intake was present in $71.7 \%$ and $76.2 \%$ of the children and adolescents, respectively. QbImpulsivity improvement was observed in $50.4 \%$ of the children and $44.7 \%$ of the adolescents, and QbInattention improvement in $85.1 \%$ and $91.1 \%$ of the children and adolescents, respectively. All three parameters improved simultaneously in $27.7 \%$ of the children and $28.7 \%$ of the adolescents. The likelihood that one parameter deteriorated after MPH use was greater if that parameter was within the normal range before medication. This was most pronounced for QbImpulsivity. Among male adolescents, QbInattention improvement was often accompanied by QbImpulsivity deterioration.

Conclusion: The QbTest inattention and motor activity parameters improved markedly after a single MPH dose in children and adolescents with ADHD, while less so for impulsivity. Improvement of one parameter is not necessarily associated with improvement of the other two, and deterioration, especially regarding impulsivity, may occur. If confirmed, these results highlight the need for optimization and individualization of MPH treatment, while monitoring all aspects of the ADHD symptomatology based on the QbTest performance.

Keywords: continuous performance task, inattention, impulsivity, motor activity, stimulants

\section{Introduction}

Attention-deficit/hyperactivity disorder (ADHD) is a neurodevelopmental condition presenting with three core symptom domains: inattention, hyperactivity, and impulsivity. ${ }^{1}$ There is vast heterogeneity in the expression of these symptoms, as well as in associated disorders, treatment response, neurocognitive abilities, and outcomes of adaptive functioning. ${ }^{2-4}$ Against this background, it is challenging to make a timely and accurate diagnosis and provide optimal and effective treatment, 
considering that we still rely mostly on the descriptive nature of diagnostic criteria in everyday clinical practice. Although there is strong evidence in favor of viewing ADHD dimensionally, for etiological and outcome research purposes, there is currently no consensus regarding what kinds of dimensions capture ADHD best and at which level they should be measured; ie, reported symptoms, cognitive tests, brain imaging, or other neurobiological markers. ${ }^{5}$ Objective measures, mainly assessing neurocognitive aspects, are considered to play an important role in increasing diagnostic accuracy and optimizing treatment response. ${ }^{6-8}$ Nevertheless, even after considerable amounts of research, the clinical utility of different objective ADHD measurement methods is to be confirmed. ${ }^{9}$

Continuous performance tasks (CPTs) are methods for measuring sustained and selective attention and impulsivity, ${ }^{8}$ and may have promising adjuvant roles in diagnosing and managing ADHD. ${ }^{10}$ Specific CPT parameters, including reaction time and reaction time variability (ie, average time for correct responses and its standard deviation as one of the measures of sustained attention), omission (ie, not responding to a target as a measure of selective attention), and commission errors (ie, responding to a non-target as a measure of impulsivity), along with newer modifications, such as motion tracking analysis for motor activity assessments, may be useful as clinical tools for diagnosing and monitoring ADHD in children. ${ }^{8}$ Over the past 15 years, convincing evidence has emerged for the effects of stimulant medication on CPT performance in children with ADHD. Epstein et al reported that children with ADHD who had taken a stimulant on the day of testing performed more accurately on classical CPT measures, had faster reaction times and reduced reaction time variability, compared with children without medication. ${ }^{11}$ Effects of methylphenidate (MPH) evaluated by CPT measures were evident both after one week of exposure and over several weeks of treatment. ${ }^{7,12,13}$ After a six-month MPH treatment course, CPT impulsivity composite scores had improved significantly, while this was not the case for the CPT distraction response. ${ }^{14}$ Several studies, using the Test of Variables of Attention (TOVA ${ }^{\circledR}$ ), which combines a CPT with minimal language demands and no left-right discrimination, ${ }^{15}$ showed improvement in commission scores, response time, and ADHD scores, while significant improvements regarding the omission variable were found in two of three studies. ${ }^{16-18}$ In preschoolers, the opposite results were obtained with significant improvement in omission, response time score and response time variability score, but not in the commission score, following a single dose of MPH. ${ }^{19}$ Studies using advanced CPT versions, including motion analysis, provide additional evidence. Heiser et $\mathrm{al}^{20}$ were among the first to show significant changes in all CPT parameters related to activity, impulsivity, and attentiveness two hours after MPH intake in children already receiving MPH. Their findings were confirmed by other groups who monitored the effect of stimulants on one or more core ADHD signs in children, measured by CPT and/or motion analysis. ${ }^{21-23}$

Previous studies, using the Quantified behavior Test $(\mathrm{QbTest})^{24}$ in children and/or adolescents, have shown mixed effects of MPH on reaction time or reaction time variation, omission, and commission errors, as well as motor activity (ie, distance in head movement). ${ }^{25-27}$ The QbTest is a commercially available measure (Qbtech AB, www.qbtech.com) approved by the United States Food and Drug Administration (FDA) to supplement the standard clinical assessment and evaluation of treatment interventions in ADHD. ${ }^{8,9,28,29}$ Being acceptable and feasible, ${ }^{30}$ it has quickly become a frequently utilized CPT in pediatric populations, ${ }^{28}$ especially due to the fact that it includes a motor activity analysis that targets hyperactivity as a proposed intermediate phenotype in ADHD. ${ }^{31}$

However, there is still conflicting evidence regarding the diagnostic validity of the QbTest. For example, Hult et al ${ }^{32}$ demonstrated moderate levels of diagnostic accuracy in children, while Johansson et $\mathrm{al}^{33}$ showed that the QbTest was not able to differentiate between ADHD and other neurodevelopmental conditions in adolescents. Hirsch and Christiansen ${ }^{34}$ investigated the validity predominantly in an adult population and found high sensitivity for two inattention markers (ie, omission and reaction time variability), and for the main scores obtained. Even though the overall classification rate was satisfactory, its specificity was low. Hollis et $\mathrm{al}^{28}$ found, in a pediatric population, that the QbTest may increase the efficiency of the ADHD assessment pathway, while Emser et $\mathrm{al}^{6}$ showed that when using both subjective and objective (one of which was the QbTest) measures, an ADHD diagnosis can be accurately predicted with high sensitivity in children, adolescents, and adults. The most recent study by Ulberstad et $\mathrm{al}^{35}$ with regard to diagnostic validity, showed that the QbCheck, as an online version of the QbTest, was able to discriminate between adolescents/adults with ADHD and controls, with a sensitivity of $82.6 \%$ and a specificity of $79.5 \%$. 
The performance of treated children and adolescents with ADHD on the QbTest and the ability of the test to detect medication/treatment effects have mainly been tested in small-sample studies, with a limited number of selected participants. ${ }^{25,26,36}$ Therefore, more studies are needed, using larger samples and clinical populations, in order to test how children and adolescents with ADHD perform on the QbTest, especially with regard to early identification of treatment responders. Objective measures, including CPT scores, could be used to identify children and adolescents with ADHD who will or will not respond to $\mathrm{MPH}{ }^{7,25}$

The aim of the present study was to evaluate the QbTest performance of children and adolescents with ADHD before and after a single MPH dose given in a clinical setting, thereby attempting to evaluate the sensitivity of attention functionality, impulsivity, and hyperactivity to a single MPH use.

\section{Materials and Methods Subjects}

This is a retrospective chart review study for which data were extracted from available medical records of children and adolescents who had undergone QbTest assessments at the department of child and adolescent psychiatry in one of few general hospitals located in western Sweden during the period January 1, 2004 to December 31, 2017. Data were extracted from a database containing information on the QbTest, demographics, and selected clinical data. The main inclusion criteria for the study were children and adolescents aged six to 18 years and a confirmed diagnosis of ADHD. Children with a diagnosis of autism spectrum disorder (ASD) or with severe mental illness, such as early onset psychosis and intellectual disability, were excluded. Furthermore, only those with available reliable QbTest scores were included in the analyses. Following the clinic's routine, all children and adolescents included in the study underwent the QbTest twice on the same day. Once the baseline testing had been completed, the child was given a single dose of MPH and the next, post-MPH, QbTest was performed up to three hours after MPH intake.

Based on the inclusion/exclusion criteria, 364 subjects were included in the below analyses; 149 completed the QbTest (6-12 years; for detailed information see the Instrument section) and 215 the QbTest plus (13-18 years; for detailed information see the Instrument section); for details see Table 1. The mean time between baseline and the post-MPH assessment was 92.2 minutes ( $\mathrm{SD}=$ 25.11; range 30-180), and the average MPH dose given was $31.4 \mathrm{mg}(\mathrm{SD}=9.5$; range $10-72 \mathrm{mg})$. The following MPH formulations were given: methylphenidate (Concerta) in 106 (29.1\%) tests; methylphenidate capsules with modified-release (MR; Medikinet/Ritalin) to 197 (54.1\%) patients, methylphenidate tablets (Medikinet/

Table I General Characteristics of Included Subjects $(n=364)$

\begin{tabular}{|c|c|}
\hline \multicolumn{2}{|l|}{ Gender, n (\%) } \\
\hline Male & $187(5 \mid .4)$ \\
\hline Female & $177(48.6)$ \\
\hline Age, $M^{a}\left(S D^{b}\right)$ years & $\begin{array}{l}13.58 \\
(3.38)\end{array}$ \\
\hline \multicolumn{2}{|l|}{ Test type, n (\%) } \\
\hline $\begin{array}{l}\text { QbTest }^{\mathrm{c}}(6-12 \text { years }) \\
\text { QbTest }^{\mathrm{c}} \text { plus }(13-18 \text { years })\end{array}$ & $\begin{array}{l}149(40.9) \\
215(59.1)\end{array}$ \\
\hline \multicolumn{2}{|l|}{$\mathrm{BMI}^{\mathrm{d}}, \mathrm{n}(\%)$} \\
\hline $\begin{array}{l}<I S D^{b} \\
I S D^{b} \\
>I S D^{b}\end{array}$ & $\begin{array}{l}34(9.3) \\
184(50.5) \\
139(38.2)\end{array}$ \\
\hline \multicolumn{2}{|l|}{ ADHD ${ }^{e}$ type, $n(\%)$} \\
\hline $\begin{array}{l}\text { Predominantly hyperactive-impulsive presentation } \\
\text { Predominantly inattentive presentation } \\
\text { Combined presentation } \\
\text { Unspecified type }\end{array}$ & $\begin{array}{l}140(28.6) \\
77(2 \mid .2) \\
17 \mid(47.0) \\
12(3.3)\end{array}$ \\
\hline \multicolumn{2}{|c|}{$\begin{array}{l}\text { Co-occurring psychiatric disorders diagnosed before or at the testing } \\
\mathrm{n}(\%)\end{array}$} \\
\hline $\begin{array}{l}\text { One } \\
\text { Two or more }\end{array}$ & $\begin{array}{l}125(34.3) \\
54(14.9)\end{array}$ \\
\hline \multicolumn{2}{|l|}{ Comorbidity, n (\%) } \\
\hline Tics & $5(1.4)$ \\
\hline Mixed disorder of conduct and emotions & $9(2.5)$ \\
\hline Conduct disorder & $16(4.4)$ \\
\hline Specific developmental disorder of motor function & $4(1.1)$ \\
\hline Specific developmental disorders of scholastic skills & $14(3.8)$ \\
\hline $\begin{array}{l}\text { Specific developmental disorders of speech and } \\
\text { language }\end{array}$ & $9(2.5)$ \\
\hline Nonorganic sleep disorders & $7(1.9)$ \\
\hline Reaction to severe stress or adjustment disorder & $7(1.9)$ \\
\hline Obsessive-compulsive disorder & $8(2.2)$ \\
\hline Anxiety disorder & $39(10.7)$ \\
\hline Depressive episode & $40(11)$ \\
\hline Bipolar affective disorder & $8(2.2)$ \\
\hline Other & $13(3.6)$ \\
\hline
\end{tabular}

Notes: a M, mean; ${ }^{\mathrm{b}} \mathrm{SD}$, standard deviation; ${ }^{\mathrm{C} Q b T e s t}$, Quantified behavior Test; ${ }^{\mathrm{d}} \mathrm{BMI}$, body mass index; ${ }^{\mathrm{e}} \mathrm{ADHD}$, attention-deficit/hyperactivity disorder. 
Ritalin) to 17 (4.7\%) patients, and methylphenidate (drug name not specified or MPH formulation capsule with MR/ tablet unknown) to $44(12.1 \%)$ patients. In total, eight $(2.2 \%)$ children and adolescents were drug-naïve, 38 $(10.4 \%)$ received other-than-MPH medication, and twelve $(3.3 \%)$ were already treated with stimulants. For the rest of the sample, no reliable data were available on previous or current psychopharmacological treatment.

\section{Instrument and Procedures}

The QbTest, as a combination of a computerized CPT and a motion tracking system, provides data for the three core signs of ADHD, namely attention, hyperactivity, and impulsivity. ${ }^{24,35,37}$ During a CPT task, which measures sustained and selective attention and impulsivity, ${ }^{8}$ a highresolution infrared camera monitors the participant's head movements during responses to stimuli appearing on the computer screen. The participant is seated on a stool with no back support or armrest. There are two versions of the test; one for 6 to 12-year-old children (QbTest [6-12 yrs.]) lasting 15 minutes, and the adolescent/adult version for the age of 12 to 60 years (in future text, the QbTest plus [1318 yrs.]) lasting 20 minutes. The QbTest involves presentation of two different stimuli: a gray circle (target) and a gray circle with a cross (non-target). In the QbTest plus, the CPT involves rapid presentation of four different stimuli; a red and a blue circle, and a red and a blue square. During the test, the participant is asked to press a button once in response to every target signal that is identical in color and shape to the stimulus immediately preceding it. The QbTest program gives a summary of the participant's scores after completing the test. ${ }^{26}$ These results are presented as raw scores as well as Q-scores that are calculated using the normative data matched for gender and age. ${ }^{35,37}$

Three cardinal parameters, QbInattention, QbActivity and QbImpulsivity, provide a summary index of the CPT and motion capture data. ${ }^{37}$ QbActivity includes data measured by the motion-capturing device, only from the second half of the test and based on the following parameters: time active (in percentage [\%]), distance (in meters [m]), area (in $\mathrm{cm}^{2}$ ), and microevents (ie, a number of the marker changes its position more than one millimeter). The motion simplicity (\%) parameter is also calculated by measuring the complexity of the movement. QbInattention and QbImpulsivity are parameters based on the CPT data. They both include parameters: omission errors (\%), reaction time (in milliseconds $[\mathrm{ms}]$ ), and reaction time variation (ms), commission errors (\%), and normalized commission errors. However, not all parameters have the same weight in these two cardinal parameters. For QbInattention, omission errors, reaction time, and reaction time variation are the parameters with the greatest weight, and for QbImpulsivity, the corresponding items are commission errors and normalized commission errors. For the QbTest for 6 to 12-year-olds, anticipatory errors (ie, a response detected a little before or just after a stimulus is presented) are also included for QbImpulsivity. QbImpulsivity includes data from the second to the fourth quartile, while QbInattention only includes data from quartiles three and four. The cardinal parameters, QbInattention, QbActivity and QbImpulsivity, were derived from a prior factor analysis, ${ }^{37}$ and results are standardized to Q-scores (ie, transformation of a skewed statistical distribution to normally distributed Z-scores, where the mean equals 0 and the standard deviation equals 1). ${ }^{9}$ Thus, the cardinal parameters inform on differences between a patient's raw score and the score of an age and gender-matched control. ${ }^{37,38} \mathrm{~A}$ Q-score of 1.5 or higher is interpreted as atypical ${ }^{34}$ and a Qscore of 1.5 corresponds to the $93^{\text {rd }}$ percentile. ${ }^{37}$ The value of the Q-score ranging from 1.1 to 1.4 is interpreted as slightly atypical. ${ }^{39}$ In the present study, a Q-score $>1$ was considered to be atypical. The Q-score of 1.1 is equivalent to the 86th percentile, ${ }^{40}$ which means that $86 \%$ of the normative group (same age and gender) will score lower than the person who has obtained these results on the test. After the MPH challenge, a decrease by $\geq 0.5$ of the score was considered as improvement and an increase by $\geq 0.5$ as deterioration. Tallberg et al considered a decrease in QbTest scores of more than $0.4 \mathrm{SD}$ as a clinically significant improvement. ${ }^{9}$

Previous psychometric studies demonstrated sound measurement properties of the Qbtest, including good test-retest reliability. ${ }^{35}$ In the present study, the test-retest reliability of the cardinal parameters was analyzed using the intra-class correlation coefficient $\left(\mathrm{ICC}^{41}{ }^{4}\right.$ ) in a subgroup of children and adolescents whose Q-scores remained in the same percentile range after the MPH dose (ie, remained unchanged). The ICC of QbActivity was 0.5 for the data from 83 children and 0.75 for the data from 103 adolescents. For QbImpulsivity, the ICC was 0.83 for the data from 111 children and 0.80 for the data from 136 adolescents. For QbInattention, the ICC was 0.64 for the data from 75 children and 0.36 for the data from 97 adolescents.

Detailed information on the QbTest and description of the norm database can be found in the QbTest technical manual. ${ }^{37}$ 


\section{Ethics}

The Regional Ethical Review Board, University of Gothenburg, Sweden, approved the study (reg. no. 07218). To protect the confidentiality of the subjects, extensive precautions were taken. The first author (RK) was the only person who had access to all data systems. She coded all the subjects and was the only person/researcher who had access to the code list. All data were anonymized before analysis. No informed consent was used. The application that was approved by the Regional Ethical Review Board included detailed information on this procedure. The Regional Ethical Review Board did not request informed consent from the participants.

\section{Statistical Analyses}

The difference in QbTest parameters between baseline and post-MPH was analyzed with the paired $t$-test for children (QbTest 6-12 yrs.) and adolescents (QbTest plus 13-18 yrs.) separately, while differences between baseline and post-MPH tests for both groups together were analyzed by analysis of variance (ANOVA). Cohen's d effect size was calculated and its values were interpreted as small ( $<$ $0.5)$, medium $(0.5-0.8)$ or large $(>0.8) .{ }^{42}$ Changes in scores from baseline to post-test were calculated for each child/adolescent with respect to the three parameters, and the correlation analysis was performed to explore whether the magnitude of changes to these parameters was correlated (ie, Pearson's r correlation coefficient). The strength of the correlations was interpreted as weak (0.1-0.3), moderate $(0.31-0.5)$ or high $(>0.51)$. Multiple regression analysis was then used to test which variables significantly predicted changes in three Q-scores from baseline to the post-MPH assessment. Significant changes were calculated here as absolute changes in the scores ( + or $-\geq 0.5$ ) or not, according to the baseline score classification of the results as atypical or typical. Finally, the multinomial logistic regression analysis was carried out to test for the predictors of no changes and deteriorations compared with improvements of the three Q-scores. For each score, the initial model used one dependent variable, a change in the score (ie, no change, improvement, and deterioration), with those improved as the reference category, and the following predictors: gender, QbTest type (6-12 vs 1318 ), body mass index (BMI) category, ADHD type, number of comorbidities, time passed between MPH intake and the second test occasion, MPH dose given, the QbActivity, QbImpulsivity or QbInattention score on the first test occasion, categorized as above 1.0 vs below 1.0 , and the change in the other two scores (ie, no change, improvement, and deterioration).

\section{Results}

The mean values (SD) for the objective QbTest parameters at baseline and post-MPH in children (QbTest) and adolescents (QbTest plus) are presented in Table 2. Except for the anticipatory parameter, all scores were significantly decreased at the post-MPH assessment for children. Cohen's d effect sizes were moderate to large. All scores for the adolescents were significantly decreased at the post-MPH assessment, and the effect size ranged from moderate to large, except for the commission errors, which were low.

The distribution of subjects with regard to changes in scores from baseline to the post-MPH assessment is given for the cardinal parameters by gender and as totals in Table 3 . Improved QbActivity scores were present in $71.7 \%$ of the children and $76.2 \%$ of the adolescents, improved QbImpulsivity scores in $50.4 \%$ of the children and $44.7 \%$ of the adolescents, and improved QbInattention scores in $85.1 \%$ of the children and $91.1 \%$ of the adolescents. For children, there were no statistically significant differences between males and females for any of the three scores, while for adolescents, a statistically significant difference was observed for QbImpulsivity only $\left(\chi_{(\mathrm{df})}^{2}=8.65(2), \mathrm{p}=\right.$ $0.013)$. In addition, a statistically significant difference was observed for QbImpulsivity between male children and adolescents $\left(\chi_{(\mathrm{df})}^{2}=18.55(2), \mathrm{p}<0.01\right)$. For females, a statistically significant difference between children and adolescents was observed for QbActivity $\left(\chi_{(\mathrm{df})}^{2}=7.85(2), \mathrm{p}=0.02\right)$.

All three parameters improved simultaneously in $27.7 \%$ of the children and $28.7 \%$ of the adolescents Additionally, $26.2 \%$ of the children and $33 \%$ of the adolescents improved on QbInattention and QbActivity, $14.9 \%$ of the children and $10 \%$ of the adolescents on QbInattention and QbImpulsivity, and 3.5\% of the children and $4.8 \%$ of the adolescents on QbActivity and QbImpulsivity, when the third Q-score remained unchanged or deteriorated. The greatest difference by gender in deterioration was in the QbImpulsivity score for adolescents; $33.8 \%$ of the males and $21.8 \%$ of the females had a deterioration of this score combined with an improvement in QbInattention. Details on different age and gender groups compared are given in Appendix $\underline{1,2,}$ and $\underline{3}$. 
Table 2 Objective Measures of Activity, Impulsivity and Inattention at Baseline and Post-MPH in Children (QbTest) and Adolescents (QbTest Plus)

\begin{tabular}{|c|c|c|c|c|c|c|c|c|}
\hline \multirow[b]{2}{*}{ Measure } & \multirow[b]{2}{*}{$\mathbf{n}$} & \multicolumn{3}{|c|}{ QbTest $^{\text {b }}\left(6-12\right.$ yrs. $\left.^{c}\right)$} & \multicolumn{4}{|c|}{ 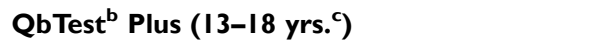 } \\
\hline & & $\begin{array}{l}\text { Before } \\
\text { MPH }^{\mathrm{a}}\end{array}$ & After $M P^{a}$ & $p, d^{d}$ & $\mathbf{n}$ & $\begin{array}{l}\text { Before } \\
\text { MPH }^{\mathrm{a}}\end{array}$ & After $\mathbf{M P H}^{\mathrm{a}}$ & $p, d^{d}$ \\
\hline Time active (\%) & 120 & $42.03(25.42)$ & $27.44(26.52)$ & $<0.01,0.69$ & 194 & $25.5 \mathrm{I}(20.56)$ & $11.84(17.45)$ & $<0.01,0.74$ \\
\hline Distance $(m)$ & 122 & $17.89(13.52)$ & $11.30(12.18)$ & $<0.01,0.64$ & 194 & II.72 (9.98) & $5.99(5.64)$ & $<0.01,0.64$ \\
\hline Area $(\mathrm{cm} 2)$ & 122 & $71.23(50.47)$ & $40.19(44.39)$ & $<0.01,0.82$ & 194 & $49.25(40.84)$ & $20.48(25.09)$ & $<0.01,0.76$ \\
\hline Microevents & 122 & $\begin{array}{l}10,034.42 \\
(5801.86)\end{array}$ & $\begin{array}{l}6792.68 \\
(5589.06)\end{array}$ & $<0.01,0.69$ & 194 & $\begin{array}{l}6652.67 \\
(4780.96)\end{array}$ & $\begin{array}{l}3505.66 \\
(3415.49)\end{array}$ & $<0.01,0.75$ \\
\hline Motion simplicity (\%) & 120 & $47.94(6.94)$ & $41.64(8.55)$ & $<0.01,0.76$ & 194 & $48.31(10.62)$ & 37.79 (11.55) & $<0.01,1.00$ \\
\hline Commission errors (\%) & 147 & $18.85(13.92)$ & $12.49(12.05)$ & $<0.01,0.61$ & 213 & $3.35(5.58)$ & $2.14(3.26)$ & $<0.01,0.24$ \\
\hline Anticipatory (\%) & 147 & $3.04(5.24)$ & $2.93(7.13)$ & 0.28 & I & I & l & I \\
\hline Reaction time (ms) & 147 & $\begin{array}{l}529.04 \\
(111.52)\end{array}$ & $\begin{array}{l}471.38 \\
(98.21)\end{array}$ & $<0.01,0.85$ & 214 & $\begin{array}{l}635.15 \\
(131.53)\end{array}$ & $\begin{array}{l}498.90 \\
(92.26)\end{array}$ & $<0.01$, I.II \\
\hline $\begin{array}{l}\text { Reaction time } \\
\text { variation }(\mathrm{ms})\end{array}$ & 125 & $221.59(95.24)$ & $\begin{array}{l}162.79 \\
(93.90)\end{array}$ & $<0.01,0.80$ & 181 & $\begin{array}{l}224.23 \\
(60.66)\end{array}$ & $\begin{array}{l}155.35 \\
(50.83)\end{array}$ & $<0.01,1.06$ \\
\hline $\begin{array}{l}\text { Normalized reaction } \\
\text { time (\%) }\end{array}$ & 125 & $41.68(15.46)$ & $33.84(16.68)$ & $<0.01,0.68$ & 181 & $35.59(7.33)$ & $31.09(7.17)$ & $<0.01,0.58$ \\
\hline Omission errors (\%) & 147 & I7.3| (17.18) & $8.25(\mid 3.80)$ & $<0.01,0.74$ & 206 & $28.58(19.64)$ & $8.45(10.86)$ & $<0.01,1.06$ \\
\hline
\end{tabular}

Notes: ' $\mathrm{MPH}$, methylphenidate; ${ }^{\mathrm{b}} \mathrm{QbTest}$, Quantified behavior Test; ${ }^{\mathrm{y}}$ rs., years: ${ }^{\mathrm{d}} \mathrm{p}, \mathrm{p}$ value for $t$-test; $\mathrm{d}$, Cohen's $\mathrm{d}$ effect size.

\section{Predictors of Change}

The correlation between the changes in score means from baseline to the post-MPH testing of the three cardinal parameters was generally weak (ranging 0.15-0.26), while it could be negligible to moderate according to the 95\% confidence interval (range 0.04-0.36).
The results of multiple linear regressions are given in Table 4. The predictors included in the model of multiple regression analysis explained $31 \%$ of the variance $\left(\mathrm{F}_{(10}\right.$, $\left.{ }_{106)}=4.71, \mathrm{p}<0.01\right)$ for children and $25 \%$ of the variance $\left(F_{(10,170)}=5.86, p<0.01\right)$ for adolescents in the change in QbActivity. A QbActivity score at first test accounted for

Table 3 Distribution of Changes in Scores for Three Cardinal Parameters

\begin{tabular}{|c|c|c|c|c|c|c|c|}
\hline & & \multicolumn{3}{|c|}{ QbTest $^{a}\left(6-12\right.$ yrs. $\left.^{b}\right)$} & \multicolumn{3}{|c|}{ QbTest $^{a}$ Plus (13-18 yrs. $\left.{ }^{b}\right)$} \\
\hline & & Male, n (\%) & Female, n (\%) & Total, n (\%) & Male, n (\%) & Female, n (\%) & Total, n (\%) \\
\hline \multirow[t]{3}{*}{ QbActivity } & No change & $18(23.4)$ & $6(14.0)$ & $24(20.0)$ & $15(19.0)$ & $25(21.9)$ & $40(20.7)$ \\
\hline & Improvement & $54(70.1)$ & $32(74.4)$ & 86 (7I.7) & $60(75.9)$ & $87(76.3)$ & 147 (76.2) \\
\hline & Deterioration & $5(6.5)$ & $5(11.6)$ & $10(8.3)$ & $4(5.1)$ & $2(1.8)$ & $6(3.1)$ \\
\hline \multirow[t]{3}{*}{ Qblmpulsivity } & No change & $33(35.9)$ & $23(46.9)$ & $56(39.7)$ & $21(24.7)$ & $38(30.9)$ & $59(28.4)$ \\
\hline & Improvement & $5 \mathrm{I}(55.4)$ & $20(40.8)$ & 71 (50.4) & $34(40.0)$ & $59(48.0)$ & $93(44.7)$ \\
\hline & Deterioration & $8(8.7)$ & $6(12.2)$ & $14(9.9)$ & $30(35.3)$ & $26(21.1)$ & $56(26.9)$ \\
\hline \multirow[t]{3}{*}{ Qblnattention } & No change & $6(6.5)$ & $4(8.2)$ & $10(7.1)$ & $6(7.2)$ & $7(5.9)$ & $13(6.4)$ \\
\hline & Improvement & $76(82.6)$ & $44(89.8)$ & $120(85.1)$ & 74 (89.2) & 110 (92.4) & I84 (9I.I) \\
\hline & Deterioration & $10(10.9)$ & I (2.0) & II (7.8) & $3(3.6)$ & $2(1.7)$ & $5(2.5)$ \\
\hline
\end{tabular}

Notes: ${ }^{a}$ QbTest, Quantified behavior Test; ${ }^{b}$ yrs., years. 
Table 4 Results of Multiple Linear Regression

\begin{tabular}{|c|c|c|c|c|c|c|}
\hline & \multicolumn{3}{|c|}{$\begin{array}{l}\text { QbTest }^{\text {a }}(6-12 \\
\left.\text { yrs. }^{\text {b }}\right)\end{array}$} & \multicolumn{3}{|c|}{$\begin{array}{l}\text { QbTest }^{\mathrm{a}} \text { Plus (13- } \\
\left.\text { 18 } \text { yrs. }^{\mathrm{b}}\right)\end{array}$} \\
\hline & $B^{f}$ & SE $^{g}$ & $\mathbf{p}^{\mathbf{h}}$ & $B^{f}$ & SE $^{g}$ & $\mathbf{p}^{\mathbf{h}}$ \\
\hline \multicolumn{7}{|c|}{ Change in QbActivity } \\
\hline Gender & 0.06 & 0.22 & 0.77 & -0.13 & 0.16 & 0.41 \\
\hline Age in years & 0.23 & 0.07 & $\begin{array}{l}< \\
0.01\end{array}$ & -0.01 & 0.05 & 0.88 \\
\hline $\mathrm{BMI}^{\mathrm{C}}$ category & 0.40 & 0.17 & 0.02 & 0.17 & 0.12 & 0.17 \\
\hline ADHDd type & -0.15 & 0.14 & 0.27 & -0.02 & 0.09 & 0.76 \\
\hline $\begin{array}{l}\text { Number of } \\
\text { comorbidities }\end{array}$ & 0.11 & 0.14 & 0.41 & -0.11 & 0.09 & 0.24 \\
\hline $\begin{array}{l}\text { Time lapsed after } \\
\mathrm{MPH}^{\mathrm{e}}\end{array}$ & -0.01 & 0.01 & 0.36 & 0.01 & 0.01 & 0.97 \\
\hline $\mathrm{MPH}^{\mathrm{e}}$ dose given & -0.02 & 0.01 & 0.17 & 0.01 & 0.01 & 0.76 \\
\hline $\begin{array}{l}\text { QbActivity at } \\
\text { baseline }\end{array}$ & 0.54 & 0.10 & $\begin{array}{l}< \\
0.01\end{array}$ & 0.33 & 0.07 & $\begin{array}{l}< \\
0.01\end{array}$ \\
\hline $\begin{array}{l}\text { Qblmpulsivity } \\
\text { change }\end{array}$ & 0.10 & 0.11 & 0.37 & 0.11 & 0.06 & 0.07 \\
\hline $\begin{array}{l}\text { Qblnattention } \\
\text { change }\end{array}$ & 0.17 & 0.07 & 0.03 & 0.23 & 0.06 & $\begin{array}{l}< \\
0.01\end{array}$ \\
\hline \multicolumn{7}{|c|}{ Change in Qblmpulsivity } \\
\hline Gender & -0.27 & 0.16 & 0.10 & -0.21 & 0.16 & 0.21 \\
\hline Age in years & 0.06 & 0.05 & 0.20 & -0.06 & 0.05 & 0.24 \\
\hline $\mathrm{BMI}^{\mathrm{C}}$ category & -0.12 & 0.13 & 0.36 & -0.06 & 0.12 & 0.59 \\
\hline$A D H D^{d}$ type & 0.08 & 0.11 & 0.42 & -0.10 & 0.09 & 0.27 \\
\hline $\begin{array}{l}\text { Number of } \\
\text { comorbidities }\end{array}$ & -0.02 & 0.11 & 0.84 & 0.04 & 0.09 & 0.71 \\
\hline $\begin{array}{l}\text { Time lapsed after } \\
\mathrm{MPH}^{\mathrm{e}}\end{array}$ & -0.01 & 0.01 & 0.53 & -0.04 & 0.01 & 0.05 \\
\hline $\mathrm{MPH}^{\mathrm{e}}$ dose given & -0.01 & 0.01 & 0.71 & 0.02 & 0.01 & 0.03 \\
\hline $\begin{array}{l}\text { Qblmpulsivity at } \\
\text { baseline }\end{array}$ & 0.40 & 0.06 & $\begin{array}{l}< \\
0.01\end{array}$ & 0.65 & 0.06 & $\begin{array}{l}< \\
0.01\end{array}$ \\
\hline $\begin{array}{l}\text { Qblnattention } \\
\text { change }\end{array}$ & 0.15 & 0.06 & 0.01 & 0.12 & 0.06 & 0.06 \\
\hline QbActivity change & 0.12 & 0.06 & $\begin{array}{l}< \\
0.05\end{array}$ & 0.21 & 0.07 & $\begin{array}{l}< \\
0.01\end{array}$ \\
\hline \multicolumn{7}{|c|}{ Change in Qblnattention } \\
\hline Gender & 0.17 & 0.23 & 0.45 & 0.16 & 0.15 & 0.28 \\
\hline Age in years & 0.08 & 0.07 & 0.25 & 0.08 & 0.05 & 0.08 \\
\hline $\mathrm{BMI}^{\mathrm{C}}$ category & 0.03 & 0.19 & 0.86 & -0.15 & 0.11 & 0.12 \\
\hline ADHD ${ }^{d}$ type & -0.06 & 0.15 & 0.66 & 0.07 & 0.08 & 0.42 \\
\hline $\begin{array}{l}\text { Number of } \\
\text { comorbidities }\end{array}$ & -0.11 & 0.15 & 0.44 & -0.01 & 0.09 & 0.99 \\
\hline $\begin{array}{l}\text { Time passed after } \\
\mathrm{MPH}^{\mathrm{e}}\end{array}$ & 0.01 & 0.01 & 0.45 & -0.01 & 0.01 & 0.36 \\
\hline $\mathrm{MPH}^{\mathrm{e}}$ dose given & 0.01 & 0.01 & 0.98 & 0.02 & 0.01 & 0.09 \\
\hline $\begin{array}{l}\text { Qblnattention at } \\
\text { baseline }\end{array}$ & 0.56 & 0.09 & $\begin{array}{l}< \\
0.01\end{array}$ & 0.63 & 0.06 & $\begin{array}{l}< \\
0.01\end{array}$ \\
\hline
\end{tabular}

(Continued)
Table 4 (Continued).

\begin{tabular}{|c|c|c|c|c|c|c|}
\hline & \multicolumn{3}{|c|}{$\begin{array}{l}\text { QbTest }^{\text {a }}(6-12 \\
\left.\text { yrs. }^{\text {b }}\right)\end{array}$} & \multicolumn{3}{|c|}{$\begin{array}{l}\text { QbTest }^{\mathrm{a}} \text { Plus (13- } \\
\left.\text { 18 } \text { yrs. }^{\mathrm{b}}\right)\end{array}$} \\
\hline & $B^{f}$ & $\mathbf{S E}^{\mathrm{g}}$ & $\mathbf{p}^{\mathbf{h}}$ & $B^{f}$ & SE $^{\mathrm{g}}$ & $\mathbf{p}^{\mathbf{h}}$ \\
\hline QbActivity change & 0.16 & 0.09 & 0.07 & 0.21 & 0.06 & $\begin{array}{l}< \\
0.01\end{array}$ \\
\hline $\begin{array}{l}\text { Qblmpulsivity } \\
\text { change }\end{array}$ & 0.08 & 0.12 & 0.51 & 0.13 & 0.05 & 0.02 \\
\hline
\end{tabular}

Notes: ${ }^{\mathrm{a} Q b T e s t}$, Quantified behavior Test; ${ }^{\mathrm{b}}$ yrs., years; 'BMI, body mass index; ${ }^{\mathrm{d}} \mathrm{ADHD}$, attention-deficit/hyperactivity disorder; ${ }^{\mathrm{e}} \mathrm{MPH}$, methylphenidate; ${ }^{\mathrm{f} B}$, estimated multinomial logistic regression coefficients; ${ }^{g} \mathrm{SE}$, standard error; ${ }^{\mathrm{h}} \mathrm{p}, \mathrm{P}$ value from $t$-test.

most of the variance in the changes in both groups $(20 \%$ and $16 \%$, respectively), with the change in score for QbInattention significantly predicting additional variances, while age and BMI were significant predictors for children's scores only. For the change in QbImpulsivity, the predictors included in the model explained $32 \%$ of the variance $\left(\mathrm{F}_{(10,106)}=3.69, \mathrm{p}<0.01\right)$ for children, and $51 \%$ of the variance $\left(\mathrm{F}_{(10,170)}=18.01, \mathrm{p}<0.01\right)$ for adolescents. The QbImpulsivity score at the first test accounted for most of the variance in the changes for both groups ( $24 \%$ and $46 \%$, respectively), with a change in the QbActivity score significantly predicting additional variances in both groups, while a change in the QbInattention score significantly predicting an additional variance among children and MPH dose predicting an additional variance among adolescents. For the change in QbInattention, the predictors included in the model explained $33 \%$ of the variance $\left(\mathrm{F}_{(10,106)}=5.13, \mathrm{p}<0.01\right)$ for children and $45 \%$ of the variance $\left(\mathrm{F}_{(10,170)}=14.01, \mathrm{p}<\right.$ $0.01)$ for adolescents. The QbInattention score at the first assessment accounted for most of the variance in changes for both groups (25\% and 33\%, respectively), with the changes in the QbActivity and QbImpulsivity scores accounting for an additional variance among adolescents only.

Finally, the results of the multinomial logistic regression analysis testing for the predictors of no change vs deterioration of the three Q-scores are given in Table 5. For QbActivity, model 1 with the predictors tested did not reach statistical significance, $\chi_{(32,291)}^{2}=37.09, \mathrm{p}=0.25$, and the only statistically significant predictor for deterioration was the QbActivity score at the first test $(\mathrm{B}=2.17$, $\mathrm{p}$ $<0.01)$. We thus culled the model to exclude all predictors 
Table 5 Results of Multinomial Logistic Regressions

\begin{tabular}{|c|c|c|c|c|c|c|c|}
\hline & \multirow[t]{2}{*}{$\mathbf{B}^{\mathbf{c}}$} & \multirow[t]{2}{*}{$\mathbf{S E}^{\mathbf{d}}$} & \multirow[t]{2}{*}{ Wald $^{e}$ (dff) } & \multirow[t]{2}{*}{$p^{g}$} & \multirow[t]{2}{*}{$\operatorname{Exp}(B)^{h}$} & \multicolumn{2}{|c|}{$95 \% \mathrm{Cl}^{\mathrm{i}}$ for $\operatorname{Exp}(\mathrm{B})^{\mathrm{h}}$} \\
\hline & & & & & & $\mathbf{L B}^{\mathbf{j}}$ & $\mathbf{U B}^{\mathrm{k}}$ \\
\hline \multicolumn{8}{|l|}{ Model I* } \\
\hline \multicolumn{8}{|l|}{ QbActivity, deterioration } \\
\hline QbActivity score $\leq 1.0$ at baseline & 2.35 & 0.76 & $9.4 I(I)$ & $<0.01$ & 10.54 & 2.34 & 47.44 \\
\hline \multicolumn{8}{|l|}{ Model 2* } \\
\hline \multicolumn{8}{|l|}{ Qblmpulsivity, no change } \\
\hline $\mathrm{MPH}^{\mathrm{a}}$ dose given & -0.05 & 0.01 & $8.01(1)$ & $<0.01$ & 0.94 & 0.91 & 0.98 \\
\hline Male gender & -0.65 & 0.31 & $4.31(1)$ & 0.04 & 0.52 & 0.28 & 0.96 \\
\hline Qblmpulsivity score $\leq 1.0$ at baseline & 1.54 & 0.33 & $21.61(I)$ & $<0.01$ & 4.69 & 2.44 & 8.98 \\
\hline No change in Qblnattention & -1.98 & 0.96 & $4.19(1)$ & 0.04 & 0.14 & 0.02 & 0.92 \\
\hline \multicolumn{8}{|l|}{ Qblmpulsivity, deterioration } \\
\hline QbTest $^{\mathrm{b}}$ (6-12 yrs.) & -1.65 & 0.48 & II.77 (I) & $<0.01$ & 0.19 & 0.07 & 0.49 \\
\hline Qblmpulsivity score $\leq 1.0$ at baseline & 3.61 & 0.60 & $35.58(\mathrm{I})$ & $<0.01$ & 36.89 & 11.27 & $|20.7|$ \\
\hline No change in Qblnattention & -3.73 & 1.28 & $8.49(1)$ & $<0.01$ & 0.02 & 0.01 & 0.29 \\
\hline Improvement in Qblnattention & -2.56 & 1.01 & $6.35(\mathrm{I})$ & 0.01 & 0.08 & 0.01 & 0.57 \\
\hline \multicolumn{8}{|l|}{ Model 3* } \\
\hline \multicolumn{8}{|l|}{ Qblnattention No change } \\
\hline $\mathrm{MPH}^{\mathrm{a}}$ dose given & -0.07 & 0.03 & $4.93(\mathrm{I})$ & 0.00 & 0.93 & 0.87 & 0.99 \\
\hline Qblnattention score $\leq 1.0$ at baseline & 1.54 & 0.54 & $7.97(\mathrm{I})$ & $<0.01$ & 4.67 & 1.60 & 13.58 \\
\hline \multicolumn{8}{|l|}{ Qblnattention, deterioration } \\
\hline $\mathrm{MPH}^{\mathrm{a}}$ dose given & -0.08 & 0.03 & $4.15(1)$ & 0.01 & 0.93 & 0.86 & 0.99 \\
\hline Male gender & 1.41 & 0.71 & $3.87(\mathrm{I})$ & $<0.05$ & 4.12 & 1.01 & 16.83 \\
\hline Qblnattention score $\leq 1.0$ at baseline & 1.53 & 0.63 & $5.91(1)$ & 0.02 & 4.63 & 1.35 & 15.92 \\
\hline
\end{tabular}

Notes: *Improvement in a score as a reference category; ${ }^{\mathrm{a}} \mathrm{MPH}$, methylphenidate; ${ }^{\mathrm{b}} \mathrm{QbTest}$, Quantified behavior Test; ${ }^{\mathrm{C}} \mathrm{B}$, estimated multinomial logistic regression coefficient; ' $\mathrm{SE}$, standard error; ${ }^{\mathrm{e} W a l d, ~ W a l d ~ t e s t ; ~}{ }^{\mathrm{d} d f}$, degree of freedom; ${ }^{\mathrm{p}} \mathrm{p}$, P value; ${ }^{\mathrm{h}} \mathrm{Exp}(\mathrm{B})$, exponentiation of the $\mathrm{B}$ coefficient; ${ }^{\mathrm{i}} \mathrm{Cl}$, confidence interval; ${ }^{\mathrm{i}} \mathrm{LB}$, lower bounds; kUB, upper bounds.

that did not have significant unique effects, and the resulting model was statistically significant, $\chi_{(2)}^{2}=16.25, \mathrm{p}<$ 0.01 . The model explained $7 \%$ of the variance and the overall percentage for correct classifications was $74.4 \%$. Only the QbActivity score $\leq 1$ at baseline was associated with increased likelihood of deteriorating after MPH intake.

For QbImpulsivity, model 2 with the predictors tested reached statistical significance, $\chi_{(32,291)}^{2}=117.32, \mathrm{p}<0.01$, but significant unique effects were evident for the MPH dose given, the type of QbTest, gender, QbImpulsivity score at baseline, and the change in QbInattention. The model explained $38 \%$ of the variance, and the overall percentage for correct classification for this model was 62.5\%. The QbImpulsivity score $\leq 1$ at baseline was associated with increased likelihood of remaining unchanged or deteriorating. A higher dose of MPH and male gender were associated with a small reduction in the likelihood of remaining unchanged, while children (Qbtest 6-12 yrs.) had a small reduction in the likelihood of deterioration. Those who remained unchanged on QbInattention had a lower likelihood of remaining the same on QbImpulsivity. In addition, those who remained unchanged or improved on QbInattention had a lower likelihood of deteriorating on QbImpulsivity.

For QbInattention, model 3 with all predictors tested reached statistical significance, $\chi_{(22,296)}^{2}=48.05, \mathrm{p}<0.01$. The model explained $26 \%$ of the variance and the overall percentage for correct classification for this model was $88.9 \%$. In this model, significant unique effects were evident 
for the MPH dose given, gender, and the QbInattention score at baseline. The QbInattention score $\leq 1$ at baseline was associated with increased likelihood of remaining unchanged or deteriorating. Increasing the dose of MPH was associated with a small reduction in the likelihood of remaining unchanged or deteriorating, while males were more likely than females to exhibit deterioration.

\section{Discussion}

The present clinical QbTest study demonstrated that after a single dose of MPH, almost all CPT parameters, along with the results from a motion analysis, improved in children and adolescents with ADHD. This was not the case for the anticipatory errors included in the QbImpulsivity parameter. However, not all QbTest parameters improved to the same degree and with the same potential clinical importance since the effect sizes were moderate to large. In general, these findings mirror the effects of MPH treatment already reported with regard to the $\mathrm{CPT}$ parameters reaction time, reaction time variability, and response inhibition (for review, see Coghill et $\mathrm{al}^{43}$ ). Specifically, our results closely correspond to two previous studies with the QbTest, which also tested the effects of a single MPH dose. Vogt and Williams ${ }^{25}$ demonstrated that children and adolescents had lower activity and inattention/ impulsivity measures after one MPH dose, but no change in the anticipatory parameter, the same as in our study. Günther et $\mathrm{al}^{27}$ evaluated short-acting and long-acting MPH over the course of a day and observed that the parameters for inattention and hyperactivity significantly decreased in both medication groups, whereas a decrease in commission errors was only evident with short-acting MPH. Partially different from our findings, Dam et $\mathrm{al}^{26}$ showed significant improvement in the number of omissions, reaction time, correct responses and activity, without improvement in reaction time variability, the anticipatory parameter, correct non-responses and commission errors using the QbTest. Several studies with other CPT tests have shown slightly different findings from ours; some studies have shown improvements in omission errors, ${ }^{17-19}$ commission errors, ${ }^{16-18,20,21}$ response time, ${ }^{16-19}$ and variability, ${ }^{16-20}$ while others reported no changes in omission ${ }^{16,21}$ or commission errors. ${ }^{19}$

When CPT parameters and a motion analysis of the QbTest were analyzed collectively as three cardinal parameters after MPH intake, the greatest improvement in children and adolescents was observed for inattention ( $85.1 \%$ and $91.1 \%$, respectively), following improvements for activity (71.7\% and $76.2 \%$, respectively) and, lastly, impulsivity $(50.4 \%$ and $44.7 \%$, respectively). The proportion of children and adolescents in our study that improved their post-MPH performance is relatively similar to the results of some other studies. For example, Ramtvedt et $\mathrm{al}^{36}$ showed that up to $72 \%$ of children diagnosed with ADHD improved after dextroamphetamine or MPH use in a six-week trial. In a study that evaluated the MPH response within 40 days, $84 \%$ of children and adolescents with hyperkinetic disorder had a robust treatment response with objective measures reverted to the population mean. ${ }^{25}$ Nevertheless, the proportion of those who respond to MPH is highly variable. One study with computerized neuropsychological testing, including $\mathrm{CPT}$, showed the response rate ranging from $18 \%$ to $85 \%$ after six weeks of MPH treatment, ${ }^{7}$ while a study with a classical CPT showed that $77 \%$ of children with ADHD improved with respect to the number of omission errors and 55\% improved their commission errors, after $\mathrm{MPH} .^{13}$ Dougherty et $\mathrm{al}^{44}$ for example, reported that $39 \%$ of adolescents with ADHD and conduct disorders experienced a decrease in commission errors in an acute MPH challenge on a CPT test variant.

Furthermore, our data showed that improvement of one $\mathrm{Qb}$ parameter was not necessarily associated with improvement of the other two parameters are of specific importance, since there were children and adolescents who did not change or even deteriorate in one or all parameters after MPH, which has also been reported in two previous studies. $^{13,25}$ The majority $(58.6 \%)$ of our participants improved simultaneously on all three parameters or on inattention and activity parameters together and this pattern was slightly more common among adolescents. However, among those who had improvement of one score, about one in ten had deteriorations in the other two scores. The greatest deteriorations after MPH were evident for impulsivity among adolescents. Deteriorations in the impulsivity parameter were evident for more than one in every fifth adolescent who improved in activity, and for more than one in every fourth who improved in inattention. However, the deteriorations were more pronounced among adolescent boys than girls, where impulsivity deteriorated in about every third boy who improved in activity and/or inattention, which was not the case among the children. These differences in response are slightly unexpected, since newer data indicate that male children and adolescents with ADHD may be more likely to respond to $\mathrm{MPH} .{ }^{45}$ For example, although among children, it was observed that boys improved more in commission errors than girls. ${ }^{16}$ 
Further analyses showed that the higher the levels of activity, impulsivity, and inattentiveness before $\mathrm{MPH}$ intake, the greater the improvement would be in the respective ADHD symptom dimensions. One adult study reported similar observations, where patients with the worst results on the baseline QbTest showed the greatest improvement on the follow-up test done after stimulant treatment. ${ }^{46}$ Greater improvements in activity were also associated in our study with greater improvements in inattention for both groups, while greater improvements in impulsivity were associated with greater improvements in inattention and activity in children, but with greater improvements in activity in adolescents. Greater improvements in inattention were associated with greater improvements in activity and impulsivity for adolescents. On the contrary, a large number of children, and even more adolescents, showed deterioration in impulsivity with simultaneously improved inattention, as if improved attention leads to weakened response inhibition among some test participants.

The above results could be observed through the association between the MPH dose and the performance on the QbTest parameters, especially the impulsivity and inattention domain of a CPT variant, although we did not observe significant associations with the MPH dose and the improvements in the cardinal parameters. This was most likely because more than two thirds of our subjects received 30-40 mg of MPH. Nevertheless, our results showed that the MPH dose given was related to a change in QbImpulsivity among adolescents only, and that increasing the MPH dose was associated with a smaller reduction in the likelihood of QbImpulsivity remaining unchanged. Increasing the MPH dose was also associated with a smaller reduction in the likelihood of QbInattention remaining unchanged or deteriorating. This result may be seen in the framework of previous studies which considered cognitive measures of attention. Among the first, Konrad et al showed that MPH had differential effects on attentional functions; while focused attention, alertness and sustained attention seemed to be improved following a linear trend, inhibition and set-shifting performance were enhanced at a low MPH dose but worsened at a moderate MPH dose. ${ }^{47}$ Another study showed that while attentional processing significantly improved on $40 \mathrm{mg}$ of MPH (in comparison with either placebo or MPH $20 \mathrm{mg}$ ), the impulsivity parameters were higher on a $40 \mathrm{mg} \mathrm{MPH}$ dose than in those on a $20 \mathrm{mg}$, but not in a placebo group. ${ }^{44}$ Previous reports also suggest that some CPT parameters (such as microevents and variability) may depend on the daily dose of $\mathrm{MPH},{ }^{20}$ as well as inhibitory performance may significantly increase with a low dose, while performance may decrease with a high dose of stimulants. ${ }^{27}$ In addition, our findings could also be seen through the different dose-response curves for cognitive and behavioral changes ${ }^{47}$ and the possibility that different neurobiological mechanisms underlie the attention and inhibition systems, ${ }^{48}$ but especially that the ADHD pathophysiology reflects an abnormal interchange in large-scale brain circuits, ${ }^{49}$ where the precise relationship between these functions (such as for impulsivity and attention functions) remains incompletely understood. ${ }^{50}$

We did not observe any differences in response due to different ADHD subtypes, which confirms previous reports. ${ }^{12,47}$ The heterogeneity in the causes and presentations of $\mathrm{ADHD},{ }^{4,20}$ inter-individual variability in neurotransmitters, ${ }^{4}$ and different cognitive profiles, ${ }^{7}$ may be reflected in the variability of the response to MPH found in our study, although no evidence of differences in the response to MPH was seen for different clinical subtypes. ${ }^{12,47}$ It is speculated that the complex phenomenon of ADHD hyperactivity stems from deficits in the regulatory systems, which may be correctable by MPH to varying degrees. ${ }^{23}$ The different responses to MPH for impulsivity, compared with the other two parameters, are particularly important, as they may reflect the existence of different impulsivity forms, ${ }^{51}$ different responses to MPH, as measured by CPT, due to associated aggressiveness, ${ }^{14}$ or even the notion that impulsive aggression may require adjunctive therapy in addition to primary ADHD therapy. ${ }^{52}$ Thus, it is particularly relevant to detect unexpected or idiosyncratic responses to MPH medication, in order to avoid using medication in those who may not change, but may be exposed to unwanted adverse effects, or even deteriorate, especially with regard to impulsivity. The relationship between the onset and duration of a stimulant exposure and cognitive sensitivity to MPH in humans is still not sufficiently known and needs to be studied further. ${ }^{53}$

The study's strength is in the use of data from subjects in a clinical/naturalistic setting with a large clinical sample and without exclusion of co-occurring mental conditions (except established diagnoses of ASD, early onset psychosis, and intellectual disability). Having the QbTest/QbTest-Plus results collected over 14 years made it possible to analyze children and adolescents separately. Nevertheless, the study has several limitations. Firstly, this is a chart review study 
and, hence, the data reliability could be questioned. Secondly, there were not enough data on current psychopharmacological treatment and only a small number of subjects could be classified as drug-naïve. Therefore, it was not possible to assess the "pure" effects of a single MPH dose. However, in a similar study, there were no differences between non-naïve and drug-naïve responders. ${ }^{25}$ Different doses of MPH were also given in our study, without communicating the reasoning behind this and with a tendency that a higher dose was related to a higher BMI. Thus, some adjustments for BMI were probably made. Information on the MPH dose is important because it may show that a CPT measure follows a dose-response relationship that corresponds to treatment rankings. ${ }^{22}$ For a subgroup of children there was no information on the type of MPH formulation given or whether different MPH formulations from different pharmaceutical companies were used. Among the tested children and adolescents, the precise time at which the medication was given was also unknown and there were different time frames between the two assessments. Günther et $\mathrm{al}^{27}$ observed that two hours after the initial dose of MPH, inattention and hyperactivity significantly decreased for both short-acting and long-acting formulations, but a decrease in commission errors was only evident with short-acting MPH. In addition, an earlier review showed that the effects of MPH on omission errors on CPT tests are greater in experiments using shorter duration of exposure to a stimulus, ${ }^{54}$ while Vogt and Williams state that both (short-acting and extendedrelease) formulations can be used for objective measurements of the treatment response. ${ }^{25}$ However, MPH formulations from different manufacturers have different plasma levels over time and may also have different efficacy. ${ }^{55,56}$ The two-step protocol in these cases also has certain limitations; one being the fact that we are not aware of the actual activity level for the children/adolescent between the two tests, or whether nicotine or caffeine was taken between the test occasions. When CPT is used, these two common substances must be considered in interpretations of the measure of attention. ${ }^{57}$ The other fact is that we cannot neglect possible improvements in the second test due to the previous test experience on the same day, to normal circadian fluctuations or possible contextual, motivational and personality aspects. In addition, taking the same test after a short time could lead to a possible learning effect. However, the order of the stimulus in the QbTest is randomized in order to prevent practice effects due to multiple consecutive trials. ${ }^{37}$ The handedness of the included subjects was not available from the available documentation and databases, which is another limitation, since sinistrals may show greater problems in the impulsive/hyperactivity domain than dextrals. ${ }^{58}$ Furthermore, the exact diagnostic process and diagnostic criteria that were used in clinical practice were unknown, and they have probably been changed over time. Although ADHD is a clinical diagnosis, ${ }^{59}$ the QbTest results were probably, in most cases, also available to the clinicians in the diagnostic process and it is impossible to know whether this had an impact on the diagnostic decision. The limitations of our study also lie in the fact that we had a very heterogenic group of children and adolescents in terms of co-occurring psychiatric symptoms/diagnoses. On the other hand, this mirrors the clinical reality, since co-existing psychiatric problems are the rule rather than the exception in clinical practice. $^{60}$ Psychiatric comorbidities often accompany an ADHD diagnosis, ${ }^{9,61}$ and even in a general population sample, pure ADHD is rare. ${ }^{62}$ The most frequent co-existing psychiatric diagnosis in our sample was anxiety disorder and depressive episodes. However, present depression and anxiety symptoms do not seem to affect the clinical assessment of ADHD in adolescents, ${ }^{63}$ and comorbidity should not have affected the results. ${ }^{9,47}$

Besides these limitations, our data may have some important clinical and practical implications, although more studies are needed to clarify the cognitive effects of MPH during the period of adolescence. ${ }^{53}$ Combining a CPT and a motion analysis in clinical practice with self/proxy reports of ADHD symptoms could provide valuable information about immediate responses to $\mathrm{MPH}$, which might help tailor future treatments. However, close monitoring of the therapeutic effects of MPH and the child's functionality in real life situation, will probably not mirror exactly the post-MPH performance of children and adolescents with ADHD on the QbTest, which, admittedly, is more of a laboratory setting. Thus, the results obtained in our study that indicate marked improvement in the QbTest performance of children and adolescents with ADHD after a single MPH dose, especially with regard to inattention and activity, should be interpreted with that in mind. Cognitive improvement on CPT does not necessarily reflect clinical improvement, since for example, no clinical improvement was evident in more than half of the children with ADHD who had displayed cognitive improvement on the CPT. ${ }^{13}$ The clinical relevance of cognitive enhancement by MPH needs to be further determined; thus, it is important to promote additional 
work aiming to clarify the role of cognitive dysfunctions in clinical functioning. ${ }^{53}$

\section{Conclusions}

The QbTest CPT parameters for inattention and motor activity parameters improved markedly after a single MPH dose in children and adolescents with ADHD, while the parameter for impulsivity, commission errors, changed markedly in children, and to a lesser degree in adolescents. Although the variability of responses to MPH was confirmed, every fourth child or adolescent improved on all three cardinal QbTest parameters, while improvements in one domain were not necessarily associated with other improvements, where impulsivity, in particular, may deteriorate. The higher the QbTest scores before MPH intake, the greater the improvement would be in the respective parameter. However, the likelihood that one cardinal parameter deteriorates after MPH use would be greater if that parameter was within the normal range before medication. If confirmed, these results highlight the need for optimization and individualization of the treatment with MPH, while at the same time monitoring all aspects of the ADHD symptomatology based on the QbTest performance.

\section{Abbreviations}

ADHD, attention-deficit/hyperactivity disorder; ASD, autism spectrum disorder; BMI, Body mass index; CPT, Continuous performance task; FDA, Food and Drug Administration; MPH, Methylphenidate; MR, Modifiedrelease; QbTest, The Quantified behavior Test; TOVA, Test of Variables of Attention; SD, standard deviation.

\section{Acknowledgments}

The authors would like to thank the management of the Department of Child and Adolescent Psychiatry, the Research \& Development Centre, and librarians at the Skaraborgs Hospital, as well as the Skaraborg Institute, for their support in realizing the project.

\section{Author Contributions}

All authors made a significant contribution to the work, whether to its conception, study design, execution, acquisition of data, analysis and interpretation, or in all these areas; participation in the drafting, revision or critical reviewing of the article; giving final approval of the version to be published; having agreed about the journal to which the article was submitted; and agreeing to be accountable for all aspects of the work.

\section{Funding}

The research was funded by the Research \& Development Centre, Skaraborg Hospital and Fund for Rehabilitation and Medical Research. The sponsors were not involved in any part of the project (from study design to submission of the paper for publication). The authors also declare that the research was conducted in the absence of any commercial or financial relationships with the company distributing the QbTest or any other entity related to the test, since the test is commercially available.

\section{Disclosure}

Dr Rajna Knez report grants from Fund for Rehabilitation and Medical Research, during the conduct of the study. The authors declare no other potential conflicts of interest.

\section{References}

1. American Psychiatric Association. Diagnostic and Statistical Manual of Mental Disorders. 5th ed. Arlington, VA: American Psychiatric Association; 2013.

2. Kofler MJ, Sarver DE, Spiegel JA, et al. Heterogeneity in ADHD: neurocognitive predictors of peer, family, and academic functioning. Child Neuropsychol. 2017;23(6):733-759.

3. Kofler MJ, Irwin LN, Soto EF, et al. Executive functioning heterogeneity in pediatric ADHD. J Abnorm Child Psychol. 2019;47 (2):273-286.

4. Luo Y, Weibman D, Halperin J, Li X. A review of heterogeneity in Attention Deficit/Hyperactivity Disorder (ADHD). Front Hum Neurosci. 2019;13:42.

5. Thapar A, Cooper M. Attention deficit hyperactivity disorder. Lancet. 2016;387:1240-1250.

6. Emser T, Johnston B, Steele J, et al. Assessing ADHD symptoms in children and adults: evaluating the role of objective measures. Behav Brain Func. 2018;14(1):11.

7. Elliott GR, Blasey C, Rekshan W, et al. Cognitive testing to identify children with ADHD who do and do not respond to methylphenidate. $J$ Atten Disord. 2017;21(14):1151-1160.

8. Hall CL, Valentine AZ, Groom MJ, et al. The clinical utility of the continuous performance test and objective measures of activity for diagnosing and monitoring ADHD in children: a systematic review. Eur Child Adolesc Psychiatry. 2016;25(7):677-699.

9. Tallberg $P$, Råstam $M$, Wenhov L, Eliasson G, Gustafsson $P$. Incremental clinical utility of continuous performance tests in childhood ADHD - an evidence-based assessment approach. Scand $J$ Psychol. 2019;60:26-35.

10. Ogundele MO, Ayyash HF, Banerjee S. Role of computerised continuous performance task tests in ADHD. Prog Neurol Psychiatry. 2011;15(3):8-13.

11. Epstein JN, Keith Conners C, Hervey AS, et al. Assessing medication effects in the MTA study using neuropsychological outcomes. $J$ Child Psychol Psychiatry. 2006;47(5):446-456.

12. Solanto M, Newcorn J, Vail L, et al. Stimulant drug response in the predominantly inattentive and combined subtypes of attention-deficit/ hyperactivity disorder. J Child Adolesc Psychopharmacol. 2009;19 (6):663-671. 
13. Fernández-Jaén A, Fernández-Mayoralas DM, Pardos A, et al. Clinical and cognitive response to extended-release methylphenidate (Medikinet $\left.^{(}\right)$in attention deficit/hyperactivity disorder: efficacy evaluation. Adv Ther. 2009;26(12):1097-1110.

14. Wang L-J, Huang Y-S, Chiang Y-L, et al. Clinical symptoms and performance on the continuous performance test in children with attention deficit hyperactivity disorder between subtypes: a natural follow-up study for 6 months. BMC Psychiatry. 2011;11(1):65.

15. Greenberg LM, Waldman ID. Developmental normative data on the Test of Variables of Attention (TOVA ${ }^{\mathrm{TM}}$ ). J Child Psychol Psychiatry. 1993;34(6):1019-1030.

16. Huang YS, Chao CC, Wu YY, et al. Acute effects of methylphenidate on performance during the test of variables of attention in children with attention deficit/hyperactivity disorder. Psychiatry Clin Neurosci. 2007;61(3):219-225.

17. Manor I, Meidad S, Zalsman G, et al. Objective versus subjective assessment of methylphenidate response. Child Psychiatry Hum Dev. 2008;39:273-282.

18. Murray DW, Childress A, Giblin J, et al. Effects of OROS methylphenidate on academic, behavioral, and cognitive tasks in children 9 to 12 years of age with attention-deficit/hyperactivity disorder. Clin Pediatr (Phila). 2011;50(4):308-320.

19. Peskin M, Sommerfeld E, Basford Y, et al. Continuous performance test is sensitive to a single methylphenidate challenge in preschool children with ADHD. J Atten Disord. 2016;1087054716680075.

20. Heiser P, Frey J, Smidt J, et al. Objective measurement of hyperactivity, impulsivity, and inattention in children with hyperkinetic disorders before and after treatment with methylphenidate. Eur Child Adolesc Psychiatry. 2004;13(2):100-104.

21. Tabori-Kraft J, Sørensen MJ, Kærgaard M, et al. Is OPTAx ${ }^{\mathrm{TM}}$ useful for monitoring the effect of stimulants on hyperactivity and inattention? Eur Child Adolesc Psychiatry. 2007;16(5):347-351.

22. Teicher MH, Polcari A, McGreenery CE. Utility of objective measures of activity and attention in the assessment of therapeutic response to stimulants in children with attention-deficit/hyperactivity disorder. J Child Adolesc Psychopharmacol. 2008;18(3):265-270.

23. Ohashi K, Vitaliano G, Polcari A, Teicher MH. Unraveling the nature of hyperactivity in children with attention-deficit/hyperactivity disorder. Arch Gen Psychiatry. 2010;67(4):388-396.

24. Knagenhjelm P, Ulberstad F. Quantified Behavioral Test (Qbtest) Technical Manual. Stockholm, Sweden: Qbtech; 2010.

25. Vogt C, Williams T. Early identification of stimulant treatment responders, partial responders and non-responders using objective measures in children and adolescents with hyperkinetic disorder. Child Adolesc Ment Health. 2011;16(3):144-149.

26. Dam ME, Kolmos KK, Bilenberg N. Does test dose of central stimulant influence Continuous Performance Test (CPT) and activity in boys with attention deficit hyperactivity disorder? Clin Psychiatry. 2016;2(3):13.

27. Günther T, Kahraman-Lanzerath B, Knospe EL, et al. Modulation of attention-deficit/hyperactivity disorder symptoms by short-and longacting methylphenidate over the course of a day. $J$ Child Adolesc Psychopharmacol. 2012;22(2):131-138.

28. Hollis C, Hall CL, Guo B, et al. The impact of a computerised test of attention and activity (QbTest) on diagnostic decision-making in children and young people with suspected attention deficit hyperactivity disorder: single-blind randomised controlled trial. J Child Psychol Psychiatry. 2018;59(12):1298-1308.

29. Dolgin E. FDA clearance paves way for computerized ADHD monitoring. Nat Med. 2014;20:454-455.

30. Hall CL, Valentine AZ, Walker GM, et al. Study of user experience of an objective test (QbTest) to aid ADHD assessment and medication management: a multi-methods approach. BMC Psychiatry. 2017;17(1):66.

31. Reh V, Schmidt M, Rief W, Christiansen H. Preliminary evidence for altered motion tracking-based hyperactivity in ADHD siblings. Behav Brain Func. 2014;10(1):7.
32. Hult N, Kadesjö J, Kadesjö B, et al. ADHD and the QbTest: diagnostic validity of QbTest. J Atten Disord. 2018;22(11):1074-1080.

33. Johansson V, Norén Selinus E, Kuja-Halkola R, et al. The quantified behavioral test failed to differentiate ADHD in adolescents with neurodevelopmental problems. J Atten Disord. 2018;1087054718787034.

34. Hirsch O, Christiansen H. Factorial structure and validity of the quantified behavior test plus $(\mathrm{Qb}+\mathrm{C})$. Assessment. 2017;24 (8):1037-1049.

35. Ulberstad F, Boström H, Chavanon ML, et al. Objective measurement of attention deficit hyperactivity disorder symptoms outside the clinic using the QbCheck: reliability and validity. Int J Methods Psychiatr Res. 2020;25:e1822.

36. Ramtvedt BE, Røinås E, Aabech HS, Sundet KS. Clinical gains from including both dextroamphetamine and methylphenidate in stimulant trials. J Child Adolesc Psychopharmacol. 2013;23(9):597-604.

37. Ulberstad F. QbTest Technical Manual. Stockholm, Sweden: Qbtech AB; 2016.

38. Brunkhorst-Kanaan N, Verdenhalven M, Kittel-Schneider S, Vainieri I, Reif A, Grimm O. The quantified behavioral test-a confirmatory test in the diagnostic process of adult ADHD? Front Psychiatry. 2020;11:216.

39. Available from: http://www.adhdnetwerk.nl/Content/ MeetingAttachments/47e\%20H\%20Bostr\%C3\%B6m\%20The\% 20Relevance $\% 20$ of\%20Quantified \%20Behavioral\%20Tests.pdf. Accessed June 29, 2020.

40. Available from: https://cdn2.hubspot.net/hubfs/2173087/docs/faqs/ QbTest\%20FAQ.pdf. Accessed June 29, 2020.

41. Streiner DL, Norman GR, Cairney J. Health Measurement Scales: A Practical Guide to Their Development and Use. USA: Oxford University Press; 2015.

42. Lakens D. Calculating and reporting effect sizes to facilitate cumulative science: a practical primer for t-tests and ANOVAs. Front Psychiatry. 2013;4:863.

43. Coghill DR, Seth S, Pedroso S, et al. Effects of methylphenidate on cognitive functions in children and adolescents with attention-deficit/ hyperactivity disorder: evidence from a systematic review and a meta-analysis. Biol Psychiatry. 2014;76(8):603-615.

44. Dougherty DM, Olvera RL, Acheson A, et al. Acute effects of methylphenidate on impulsivity and attentional behavior among adolescents comorbid for ADHD and conduct disorder. $J$ Adolesc. 2016;53:222-230.

45. Arns M, Vollebregt MA, Palmer D, et al. Electroencephalographic biomarkers as predictors of methylphenidate response in attentiondeficit/hyperactivity disorder. Eur Neuropsychopharmacol. 2018;28 (8):881-891.

46. Bijlenga D, Jasperse M, Gehlhaar S, Kooij JS. Objective QbTest and subjective evaluation of stimulant treatment in adult attention deficithyperactivity disorder. Eur Psychiatry. 2015;30(1):179-185.

47. Konrad K, Günther T, Hanisch C, Herpertz-Dahlmann B. Differential effects of methylphenidate on attentional functions in children with attention-deficit/hyperactivity disorder. $\mathrm{J}$ Am Acad Child Adolesc Psychiatry. 2004;43(2):191-198.

48. Riccio CA, Reynolds CR, Lowe P, Moore JJ. The continuous performance test: a window on the neural substrates for attention? Arch Clin Neuropsychol. 2002;17(3):235-272.

49. Cortese S, Castellanos FX. Neuroimaging of attention-deficit/hyperactivity disorder: current neuroscience-informed perspectives for clinicians. Curr Psychiatry Rep. 2012;14(5):568-578.

50. Elsey JW, Crowley MJ, Mencl WE, et al. Relationships between impulsivity, anxiety, and risk-taking and the neural correlates of attention in adolescents. Dev Neuropsychol. 2016;41(1-2):38-58.

51. Dalley JW, Robbins TW. Fractionating impulsivity: neuropsychiatric implications. Nat Rev Neurosci. 2017;18(3):158.

52. Saylor KE, Amann BH. Impulsive aggression as a comorbidity of attention-deficit/hyperactivity disorder in children and adolescents. $J$ Child Adolesc Psychopharmacol. 2016;26(1):19-25. 
53. Tamminga H, Reneman L, Huizenga H, Geurts H. Effects of methylphenidate on executive functioning in attention-deficit/hyperactivity disorder across the lifespan: a meta-regression analysis. Psychol Med. 2016;46:1791-1807.

54. Losier BJ, McGrath PJ, Klein RM. Error patterns on the continuous performance test in non-medicated and medicated samples of children with and without ADHD: a meta-analytic review. $J$ Child Psychol Psychiatry. 1996;37(8):971-987.

55. Banaschewski T, Coghill D, Santosh P, et al. Long-acting medications for the hyperkinetic disorders A systematic review and European treatment guideline. Child Adolesc Psychiatry. 2006;15:476-495.

56. Döpfner M, Ose C, Fischer R, Ammer R, Scherag A. Comparison of the efficacy of two different modified release methylphenidate preparations for children and adolescents with attention-deficit/hyperactivity disorder in a natural setting: comparison of the efficacy of Medikinet $[\mathrm{R}]$ retard and Concerta[R]-a randomized, controlled, double-blind multicenter clinical crossover trial. J Child Adolesc Psychopharmacol. 2011;21(5):1-10.

57. Riccio CA, Waldrop JJ, Reynolds CR, Lowe P. Effects of stimulants on the continuous performance test (CPT) implications for CPT use and interpretation. J Neuropsychiatry Clin Neurosci. 2001;13(3):326-335.
58. Simões EN, Carvalho ALN, Schmidt SL. What does handedness reveal about ADHD? An analysis based on CPT performance. Res Dev Disabil. 2017;65:46-56.

59. Söderström S, Pettersson R, Nilsson KW. Quantitative and subjective behavioural aspects in the assessment of attention-deficit hyperactivity disorder (ADHD) in adults. Nord J Psychiatry. 2014;68(1):30-37.

60. Skogli EW, Teicher MH, Andersen PN, et al. ADHD in girls and boys-gender differences in co-existing symptoms and executive function measures. BMC Psychiatry. 2013;13(1):298.

61. Giacobini M, Medin E, Ahnemark E, et al. Prevalence, patient characteristics, and pharmacological treatment of children, adolescents, and adults diagnosed with ADHD in Sweden. J Atten Disord. 2018;22(1):3-13.

62. Kadesjö B, Gillberg C. The comorbidity of ADHD in the general population of Swedish school-age children. $J$ Child Psychol Psychiatry. 2001;42(4):487-492.

63. Davidsson M, Hult N, Gillberg C, et al. Anxiety and depression in adolescents with ADHD and autism spectrum disorders; correlation between parent-and self-reports and with attention and adaptive functioning. Nord J Psychiatry. 2017;71(8):614-620.

\section{Publish your work in this journal}

Neuropsychiatric Disease and Treatment is an international, peerreviewed journal of clinical therapeutics and pharmacology focusing on concise rapid reporting of clinical or pre-clinical studies on a range of neuropsychiatric and neurological disorders. This journal is indexed on PubMed Central, the 'PsycINFO' database and CAS, and is the official journal of The International Neuropsychiatric Association (INA). The manuscript management system is completely online and includes a very quick and fair peer-review system, which is all easy to use. Visit http://www.dovepress.com/testimonials.php to read real quotes from published authors. 